\title{
Determinants of child anthropometric indicators in Ethiopia
}

Davod Ahmadi ${ }^{*}$, Ekta Amarnani ${ }^{2}$, Akankasha Sen $^{2}$, Narges Ebadi $^{2}$, Patrick Cortbaoui $^{1}$ and Hugo Melgar-Quiñonez ${ }^{1}$

\begin{abstract}
Background: Malnutrition is one of the major contributors to child mortality in Ethiopia. Currently established, child nutrition status is assessed by four anthropometric indicators. However, there are other factors affecting children's anthropometric statuses. Thus, the main objective of this paper is to explore some of the determinants of child anthropometric indicators in Ethiopia.

Methods: Data from GROW (the Growing Nutrition for Mothers and Children), a survey including 1261 mothers and 1261 children was carried out in Ethiopia in 2016. Based on the data gathered, the goal of GROW is to improve the nutritional status of women of reproductive age (15-49), as well as boys and girls under 5 years of age in Ethiopia. In order to investigate the association between different factors and child anthropometric indicators, this study employs various statistical methods, such as ANOVA, T-test, and linear regressions.

Results: Child's sex (confidence intervals for (wasting $=-0.782$, -0.151 ; stunting $=-0.936,-0.243$ ) (underweight $=-$ $0.530,-0.008$ ), child's age (confidence intervals for (wasting $=-0.020,0.007$; stunting $=-0.042,-0.011$ ) (underweight $=-0.025,-0.002$ ), maternal MUAC (confidence intervals for (wasting $=0.189,0.985 ;$ BMl-for-age $=0.077,0.895$ ), maternal education (stunting $=0.095,0.897$; underweight $=0.120,0.729$ ), and open defecation (stunting $=0.055,0$. 332; underweight $=0.042,0.257$ ) were found to be significantly associated with anthropometric indicators. Contrary to some findings, maternal dietary diversity does not present significance in aforementioned child anthropometric indicators.
\end{abstract}

Conclusion: Depending on the choice of children anthropometric indicator, different conclusions were drawn demonstrating the association between each factor to child nutritional status. Results showed child's sex, age, region, open defecation, and maternal MUAC significantly increases the risk of child anthropometric indicators. Highlighting the factors influencing child undernutrition will help inform future policies and programs designed to approach this major problem in Ethiopia.

Keywords: Child health, Child malnutrition, Developing countries, Food security, Nutrition status

\section{Background}

Malnutrition in children results in a higher disease burden and increased levels of mortality [1]. Recent evidence has shown that malnutrition is the major risk factor for children under-five years of age [2-4]. Child malnutrition is characterized with four indicators [5]: stunting (low height for age), wasting (low weight for height), underweight (low weight for age), and BMI-forage (height and weight for age). Stunting is reflective of the cumulative effects of poor nutrition or infections

\footnotetext{
*Correspondence: davod.ahmadi@mail.mcgill.ca

'McGill Institute for Global Food Security, Macdonald Campus, 21111

Lakeshore Road, Ste-Anne-de-Bellevue, QC H9X 3V9, Canada

Full list of author information is available at the end of the article
}

before or since birth; on the other hand, wasting is a measure of acute malnutrition, and is usually due to insufficient food intake or an acute onset of infectious diseases. Underweight and low BMI-for-age can reflect wasting, and are associated with an increased risk of mortality [6]. As the most prevalent form of child malnutrition, stunting affects millions of children globally [7]. Ultimately, child malnutrition impacts the growth, mortality, cognitive ability, and psychosocial development of the child [8].

As of the moment, approximately $25 \%$ of Ethiopian sub-regions (Woredas) are officially in nutritional crises. Specifically, children and women (pregnant and 
lactating) are in urgent needs for supplementary feeding and treatments of severe acute malnutrition $[9,10]$.

In Ethiopia, progress made in the reduction of child malnutrition in the last two decades were hindered at multiple levels, such as environmental (drought), political (war) and economic factors (low agricultural production, low GDP) [11, 12]. Traditionally, child undernutrition was viewed as a consequence of food shortages [13].

As the primary demographic variables, age and sex are important determinants of stunting. From chronic malnutrition studies, analysis at different ages reveals how nutritional status changes during the first three years of life [14]. Maintaining basic child dietary diversity by consuming essential nutrients and higher energy contributes directly to growth and cognitive development [15]. Maternal characteristics such as dietary diversity, [16] education, [17] Mid-Upper-Arm Circumstance (MUAC), [18] and adequacy of breastfeeding or complementary feeding practices [19-21] are also strongly linked to child anthropometric statuses.

When considering other factors influencing child growth, poor water, sanitation, and hygiene practices also play the roles of increasing health risks such as consequential diarrhea from water-borne infections [14]. According to Fenn et al. [22], improvement in sanitation is associated with reduction of stunting. When compared, children with access to toilets demonstrated lower rate of stunting to those who defecate in the open [23].

As previously stated, existing studies evaluate the effects of risk factors on either stunting, wasting, undernutrition, or BMI-for-age. Yet limited research has been shown to understand how these determinants affect all four indicators when examined together. Therefore, the purpose of this study is to assess the factors associated with the aforementioned anthropometric indications in Ethiopian children, potentially serving as base line studies for future child nutrition driven interventions.

\section{Methods}

\section{Data sources}

The data for this study was gathered from a baseline survey GROW (the Growing Nutrition for Mothers and Children) in 2016. The goal of GROW is to improve the nutritional status of women of reproductive age, as well as boys and girls under 5 years of age in Ethiopia.

\section{Sample size}

The sample was chosen by randomly selecting 14 subregions (Woredas) within each of the three Ethiopian regions (Afar, West Hararghe, and East Hararghe). Within each of the 14 sub-regions, 39 suitable villages (Kebeles) were randomly selected, of which the survey was administered to a random sample of households with children under the age of 5 .

The sampling frame for this survey was constructed using Kebele level population data obtained from government census, district and local office sources within the 12 intervention Woredas. Accordingly, 39 Kebeles were selected from 164 intervention Kebeles using probability proportional to size (PPS) technique with a total population of 276,804 as provided in the sampling frame. The calculated sample size (1310) was allocated across the 39 selected Kebeles using PPS technique based on the population size of Kebeles.

A community-based cross-sectional observational study design was employed. For children, the sample size was calculated using prevalence of key infant and young child feeding (IYCF) based on exclusive breastfeeding practices, and a target percentage point change was expected to take place at the end of the proposed intervention. For the IYCF indicators, exclusive breastfeeding was used as the key indicator for sample size determination.

In addition to mothers' and fathers' information, household characteristics, children dietary diversity, and anthropometric information were recorded. The questionnaire was validated by local experts using focus groups to ensure the translation was true to the original intent of each of the survey items. In summation, a sample of 2522 women and children was selected for this study.

\section{Outcome variables}

Children were classified as stunted, wasted, underweight, or low BMI-for age (dependent variables) based on their Z-scores for weight-for-height (WHZ), height-for-age (HAZ), weight-for-age (WAZ), and body-mass-indexfor-age (BMIZ). Children were considered stunted, wasted, or underweight if their Z-scores were less than -2 SD below the median values in reference to the United Nations World Health Organization [24].

\section{Exposure variables}

Factors that have been associated with child malnutrition in the literature were included as exposure variables in the study: maternal education, working outside, food security status, maternal dietary diversity, and maternal mid upper arm circumference (MUAC). Children's sex, age groups (i.e., $6-11 ; 12-23 ; 24-59)^{1}$, experience of diarrhea in the last two weeks (i.e., yes, no), access to sanitation facilities, and defecate openly ${ }^{2}$ were included in the analysis.

\section{Maternal characteristics}

Maternal age, as a scale variable, was recoded into four age groups: $15-24,25-29,30-39$, and $40-49$. Due to the large number of mothers who had never obtained formal education, it was recoded into two answer groups 
as "no education" and "have any education". Women's working status was evaluated using the question, "Do you work outside?" (i.e., "yes" and "no"). Maternal marital status was categorized from "married monogamous", "married polygamous", "divorced", "widowed", "single/ never married", "cohabitating with monogamous partner", "cohabitating with polygamous partner", into "married/living with partner" and "single/divorced", due to the small number of mothers in the other marital status groups.

Food security status was measured using the Food Insecurity Experience Scale (FIES), a tool produced and validated worldwide by the Food and Agriculture Organization of the United Nations. The FIES is composed of eight psycho-metric questions focusing on measuring the access aspect of food security. Responses to the eight dichotomous questions were summed $(1=$ Yes and $0=\mathrm{No}$ ), and produced into a new variable based on the summation, ranging from 0 to 8 . Those who answered negatively to all eight questions (score of 0 ) were classified as food secure. Those who answered affirmatively to one to three questions, four to six questions, or seven to eight questions were classified as "mildly food insecure," "moderately food insecure," or "severely food insecure" respectively [25].

To create maternal dietary diversity scores, questions related to the consumption of starchy staples, dark green leafy vegetables, other vitamin A rich fruits and vegetables, other fruits and vegetables, organ meats, meat and fish, eggs, legumes, nuts and seeds, milk and milk products were asked. The scores were summed, and a new score based on the summation was produced and categorized into two groups: "0-3", "4-9" [24].

\section{Children characteristics}

Children's ages were grouped into three categories: 611 months (complementary feeding), 12-23 months (transition from complementary feeding to regular), and 24-59 months (regular household diet). ${ }^{3}$ By using questions asking about children dietary diversity, the following seven food groups were summed: grains, roots and tubers, legumes and nuts, dairy products (milk, yogurt, cheese), flesh foods (meat, fish, poultry and liver/organ meats), eggs, vitamin-A rich fruits and vegetables, and other fruits and vegetables. Categories based on the summation were created- a score of zero to three indicating low diet diversity, and four to seven indicating high diet diversity [26].

\section{Household characteristics}

Household (HH)-related characteristics such as, head of $\mathrm{HH}$, number of children under $5, \mathrm{HH}$ size, $\mathrm{HH}$ electricity condition, and sanitation facilities were assessed in this study.

\section{Data analysis}

Descriptive statistics were used to examine the frequency of dependent ${ }^{4}$ and independent variables. A oneway ANOVA and t-test were used to compare the mean and SD of independent variables for each of the anthropometric indicators; differences in means were evaluated using $\mathrm{f}$-tests and $\mathrm{t}$-tests. Lastly, four linear regression analyses were carried out to explore which factors are the major determinants of children's anthropometric indicators.

\section{Results}

Socio-demographic characteristics of households, mothers and children (under 5) in study population are presented in Table 1. Seventy percent of mothers were between 25 and 39 years of age. Notably, majority of mothers were either married or living with a partner (96\%), uneducated (21\%), and working outside the home environment (36\%). Results for food insecurity status showed that $31 \%$ of mothers were food secure (31\%), and around one quarter (24\%) were malnourished, according to their MUAC. The majority of children had low dietary diversity (80.1\%). In terms of child anthropometry, around two-thirds of children were stunted (67.4\%), one-third underweight (31.6\%), one-fifth wasted (20.7\%), and one-fifth had low BMI-forage $(20.4 \%)$.

Results of t-test and ANOVA analyses are presented in Table 2. T-test analysis showed that each anthropometric indicator, except BMI-for-age, was associated statistically with child's gender. Importantly, boys had relative poor status when compared to their female counterparts. Significant differences were found between age groups and anthropometric indicators, except wasting. ANOVA analysis indicated stunting and underweighting were more prevalent in children between age 24 and 59. There was furthermore a significant difference between BMI-for age and open defecation. Regional differences were found for children's anthropometric indicators; children living in West Hararghe demonstrated the best status for all four indicators amongst other regions.

An inverse relationship between maternal education and children's anthropometric indicators status (except stunting) was observed in this study. Evidently, educated mothers appeared to have children with low levels of wasting, undernutrition and BMI-for-age when compared to mothers with no education. Additionally, significant association were found between maternal MUAC, child wasting, child underweight, and child low BMI-for-age.

Table 3 displays linear regression results for the association between child anthropometric indicators statuses and some predicting factors. Results showed that sex of children $(-0.114 ; P=0.004)$, maternal MUAC $(0.113 ; P$ 
Table 1 Maternal and household characteristics $(n=1261)$

\begin{tabular}{|c|c|c|c|}
\hline & & & N (\%) \\
\hline \multirow[t]{12}{*}{ Maternal characteristics } & Age & $15-24$ & $318(25.2)$ \\
\hline & & $25-29$ & $477(37.8)$ \\
\hline & & $30-39$ & $413(32.8)$ \\
\hline & & $40-49$ & $53(4.2)$ \\
\hline & Education & Having education & $261(20.8)$ \\
\hline & Marital & Married/living with partner & $1208(95.8)$ \\
\hline & Work outside & Yes & $454(36.0)$ \\
\hline & FIES & Food security & $302(30.8)$ \\
\hline & & Mild food insecurity & $200(20.4)$ \\
\hline & & Moderate food insecurity & $208(21.2)$ \\
\hline & & Severe food insecurity & $270(27.6)$ \\
\hline & Maternal MUAC (Centimeter) & 13-23 (Centimeter) & $306(24.3)$ \\
\hline \multirow[t]{31}{*}{ Household characteristics } & Region & Afar & $286(22.7)$ \\
\hline & & East Hararghe & $502(39.8)$ \\
\hline & & West Hararghe & $473(37.5)$ \\
\hline & Head of $\mathrm{HH}$ & Male & $1120(88.8)$ \\
\hline & Number of children under 5 & 1 & $368(29.2)$ \\
\hline & & 2 & $620(49.2)$ \\
\hline & & 3 & 209 (16.6) \\
\hline & & $4-10$ & $64(5.1)$ \\
\hline & Number of people in $\mathrm{HH}$ & $1-2$ & $12(1.0)$ \\
\hline & & 3 & $158(12.5)$ \\
\hline & & 4 & $164(13.0)$ \\
\hline & & 5 & $254(20.1)$ \\
\hline & & $6-17$ & $673(53.4)$ \\
\hline & HH Has electricity & Yes & $571(45.8)$ \\
\hline & Sanitation facilities & Improved sanitation facilities & $259(20.5)$ \\
\hline & & Open defecation & $442(35.1)$ \\
\hline & Sex & Male & $713(56.5)$ \\
\hline & & Female & $548(43.5)$ \\
\hline & Age & $6-23$ & $265(21.0)$ \\
\hline & & $24-59$ & $265(210)$ \\
\hline & Diarrhea in last two weeks & Yes & $192(15.2)$ \\
\hline & Children dietary diversity & $0-3$ & $766(80.1)$ \\
\hline & & $4-7$ & $190(19.9)$ \\
\hline & Children Anthropometric & Wasting -2SD & $135(15.4)$ \\
\hline & & Wasting -3SD & $52(5.3)$ \\
\hline & & Underweight -2SD & 205 (21.9) \\
\hline & & Underweight -3SD & $91(9.7)$ \\
\hline & & Stunting -2SD & $375(41.7)$ \\
\hline & & Stunting -3SD & $231(25.7)$ \\
\hline & & Bmi for age $-2 S D$ & $123(14.2)$ \\
\hline & & Bmi for age $-3 S D$ & $54(6.2)$ \\
\hline
\end{tabular}


Table 2 One-way Anova- and T-test analyses between anthropometric indicators and independent variables $(n=1005)$

\begin{tabular}{|c|c|c|c|c|c|c|}
\hline & & & $\begin{array}{l}\text { Wasting } \\
\text { (weight for height) }\end{array}$ & $\begin{array}{l}\text { stunting } \\
\text { (height for age) }\end{array}$ & $\begin{array}{l}\text { underweight } \\
\text { (weight for age) }\end{array}$ & BMl for age \\
\hline \multirow[t]{5}{*}{ Sex of children } & \multirow[t]{2}{*}{ Female } & Mean & 0.1484 & -1.0629 & -0.5610 & 0.2111 \\
\hline & & SD & 1.8437 & 2.2316 & 1.6612 & 1.8923 \\
\hline & \multirow[t]{3}{*}{ Male } & Mean & -0.1650 & -1.5870 & -0.9580 & -0.0181 \\
\hline & & SD & -0.2325 & 2.2905 & 1.7326 & 2.1102 \\
\hline & & T-Test & $* *$ & $* *$ & $* * *$ & n.s \\
\hline \multirow[t]{7}{*}{ Children age groups } & \multirow[t]{2}{*}{$6-11$} & Mean & -0.2064 & -0.5442 & -0.7360 & -0.2463 \\
\hline & & SD & 2.2475 & 2.5809 & 1.9379 & 2.2847 \\
\hline & \multirow[t]{2}{*}{$12-23$} & Mean & 0.0963 & -1.6473 & -0.6868 & 0.2940 \\
\hline & & SD & 1.9181 & 2.2235 & 1.7390 & 1.9574 \\
\hline & \multirow[t]{3}{*}{$24-59$} & Mean & -0.2099 & -1.5841 & -1.0242 & -0.0072 \\
\hline & & SD & 1.6772 & 1.9117 & 1.4096 & 1.8461 \\
\hline & & Anova F-Test & n.s & $* * *$ & * & $* *$ \\
\hline \multirow[t]{5}{*}{ Children Diarrhea in the last two weeks } & \multirow[t]{2}{*}{ No } & Mean & -0.0518 & -1.4115 & -0.7895 & 0.0758 \\
\hline & & SD & 1.9372 & 2.3108 & 1.6909 & 2.0274 \\
\hline & \multirow[t]{3}{*}{ Yes } & Mean & -0.1919 & -1.1421 & -0.8469 & 0.0109 \\
\hline & & SD & 1.9416 & 2.1070 & 1.8231 & 1.9541 \\
\hline & & T-Test & n.s & n.s & n.s & n.s \\
\hline \multirow[t]{5}{*}{ Children dietary diversity } & \multirow[t]{2}{*}{$0-3$} & Mean & -0.0249 & -1.3540 & -0.7196 & 0.1132 \\
\hline & & SD & 1.9155 & 2.2560 & 1.6952 & 2.0104 \\
\hline & \multirow[t]{3}{*}{$4-7$} & Mean & -0.1292 & -1.2584 & -0.8714 & -0.0069 \\
\hline & & SD & 1.9861 & 2.3718 & 1.6545 & 1.9824 \\
\hline & & T-Test & n.s & n.s & n.s & n.s \\
\hline \multirow[t]{5}{*}{ Open defecation } & \multirow[t]{2}{*}{ No } & Mean & -0.1344 & -1.6229 & -0.7763 & 0.2890 \\
\hline & & SD & 1.9714 & 2.1786 & 1.7479 & 2.0103 \\
\hline & \multirow[t]{3}{*}{ Yes } & Mean & -0.1408 & -1.3276 & -0.7327 & 0.0677 \\
\hline & & SD & 2.0227 & 2.2673 & 1.7080 & 2.1490 \\
\hline & & T-Test & n.s & n.s & n.s & $* *$ \\
\hline \multirow[t]{7}{*}{ Region } & \multirow[t]{2}{*}{ Afar } & Mean & -0.7815 & -1.0404 & -1.1039 & -0.7053 \\
\hline & & SD & 1.8165 & 2.3252 & 1.5704 & 1.9519 \\
\hline & \multirow[t]{2}{*}{ East Hararghe } & Mean & 0.1154 & -2.0501 & -1.0630 & 0.3189 \\
\hline & & SD & 1.9477 & 2.0433 & 1.6684 & 1.9991 \\
\hline & \multirow[t]{3}{*}{ West Hararghe } & Mean & 0.2112 & -0.8652 & -0.3076 & 0.3257 \\
\hline & & SD & 1.9145 & 2.3130 & 1.7391 & 1.97044 \\
\hline & & Anova F-Test & $* * *$ & $* * *$ & $* * *$ & $* * *$ \\
\hline \multirow[t]{5}{*}{ Maternal education } & \multirow[t]{2}{*}{ No education } & Mean & -0.1355 & -1.4260 & -0.8693 & 0.0116 \\
\hline & & SD & 1.9710 & 2.2208 & 1.7637 & 2.0353 \\
\hline & \multirow[t]{3}{*}{ Have education } & Mean & 0.2331 & -1.1238 & -0.4727 & 0.3394 \\
\hline & & SD & 1.8248 & 2.4981 & 1.4650 & 1.9673 \\
\hline & & T-Test & * & n.s & $* *$ & * \\
\hline \multirow[t]{4}{*}{ Maternal Muac (centimeter) } & $13-22$ & Mean & -0.5964 & -1.4673 & -1.3404 & -0.4337 \\
\hline & & SD & 1.8520 & 2.2942 & 1.6320 & 1.9981 \\
\hline & $23-34$ & Mean & 0.1342 & -1.3337 & -0.6002 & 0.2668 \\
\hline & & SD & 1.9432 & 2.2752 & 1.7006 & 2.0021 \\
\hline
\end{tabular}


Table 2 One-way Anova- and T-test analyses between anthropometric indicators and independent variables $(n=1005)$ (Continued)

\begin{tabular}{|c|c|c|c|c|c|c|}
\hline & & & $\begin{array}{l}\text { Wasting } \\
\text { (weight for height) }\end{array}$ & $\begin{array}{l}\text { stunting } \\
\text { (height for age) }\end{array}$ & $\begin{array}{l}\text { underweight } \\
\text { (weight for age) }\end{array}$ & BMl for age \\
\hline & & T-Test & $* * *$ & n.s & $* * *$ & $* * *$ \\
\hline \multirow[t]{5}{*}{ Maternal dietary diversity } & $0-3$ & Mean & -0.0711 & -1.3899 & -0.7905 & 0.0797 \\
\hline & & SD & 1.9593 & 2.2551 & 1.7291 & 2.0500 \\
\hline & $4-9$ & Mean & -0.0374 & -1.3163 & -0.7903 & 0.0762 \\
\hline & & SD & 1.9159 & 2.3378 & 1.6797 & 1.9623 \\
\hline & & T-Test & n.s & n.s & n.s & n.s \\
\hline
\end{tabular}

Chi-square significance: ${ }^{*}=p<0.05 ;{ }^{* *}=p<0.01 ;{ }^{* * *}=p<0.001 ; \mathrm{n}$. s. not significant at the threshold of $0.05 ;$ n.s Non significant

Source: Self-calculation of micro-data from Survey of Ethiopia 2016 (GROW)

$=0.004)$, and region of living $(0.141 ; P=0.000)$ remained significantly associated with prevalence of wasting. Further, sex $(-0.126 ; P=0.001)$, age $(-0.128 ; P=0.001)$, diarrhea in the last two weeks $(0.081 ; P=0.034)$, open defecation $(0.103 ; P=0.006)$, and maternal education (0.092; $P=0.015)$ contributed to the level of stunting. Results for BMI-for-age indicated that sex (-0.074; $P=0.043)$, age $(-0.084 ; P=0.021)$, open defecation (0.100; $P=0.006)$, maternal education $(0.100 ; P=0$. 006), and MUAC $(0.136 ; P=0.000)$ remained significant. Also, maternal MUAC $(0.091 ; P=0.020)$ and region of living $(0.150 ; P=0.000)$ were significantly associated with BMI-for-age. It is conclusive that girls had better anthropometric statuses comparing to their male counterparts. Also, open defecation was negatively associated with children's anthropometric status, indicating that open defecation directly contributes to degrading statuses. Children living in the Afar region had the poorest nutritional status, relatively in this study. Furthermore, mothers with better MUAC and higher education level had children with better nutritional statuses.

\section{Discussion}

More than one-quarter of Ethiopian sub-regions are in nutritional crises. So, the purpose of this study was to assess the factors associated with the anthropometric indications in Ethiopian children.

Boys had a higher prevalence of wasting, stunting, and underweight when compared to girls; no significant differences in the prevalence of low BMI-for-age were seen between sexes. These findings are corroborated by literature, demonstrating that boys are at higher risk of preterm birth [27] and exposure to environmental stress (repeated infections, and increased exposure to toxins and air pollutants) [28]. These factors potentially influence height and weight, and seems to explain the difference in anthropometric indicators between boys and girls.

While no differences were found in the prevalence of wasting between children age groups, significant differences were seen for the prevalence of stunting, underweight, and low BMI-for-age. Children of 12-59 months showed the highest risk of stunting amongst other groups. A 2016 study conducted by Gebreyesus and

Table 3 Linear regression analyses between anthropometric indicators and independent variables $(n=1005)$

\begin{tabular}{|c|c|c|c|c|c|c|c|c|c|}
\hline & & \multicolumn{2}{|c|}{$\begin{array}{l}\text { Wasting }{ }^{\mathrm{a}} \\
\text { (weight for height) }\end{array}$} & \multicolumn{2}{|c|}{$\begin{array}{l}\text { stunting } \\
\text { (height for age) }\end{array}$} & \multicolumn{2}{|c|}{$\begin{array}{l}\text { underweight } \\
\text { (weight for age) }\end{array}$} & \multicolumn{2}{|c|}{$B M l^{d}$ for age } \\
\hline & & Beta & L-H bound & Beta & L-H bound & Beta & L-H bound & Beta & L-H bound \\
\hline Independent & Sex of children & -0.114 & $-0.782,-0.151$ & -0.126 & $-0.936,-0.243$ & -0.074 & $-0.530,-0.008$ & -0.071 & $-0.627,0.022$ \\
\hline \multirow[t]{7}{*}{ variables } & Age of children & -0.036 & $-0.020,0.007$ & -0.128 & $-0.042,-0.011$ & -0.084 & $-0.025,-0.002$ & -0.041 & $-0.022,0.007$ \\
\hline & Diarrhea in last two weeks & -0.034 & $-0.629,0.241$ & 0.081 & $0.038,0.975$ & -0.029 & $-0.501,0.217$ & -0.019 & $-0.568,0.345$ \\
\hline & Open defecation & 0.007 & $-0.116,0.138$ & 0.103 & $0.055,0.332$ & 0.100 & $0.042,0.257$ & -0.006 & $-0.143,0.121$ \\
\hline & Region & 0.141 & $0.548-, 1.840$ & -0.064 & $-1.349,0.099$ & 0.061 & $-0.087,1.037$ & 0.150 & $0.647,1.989$ \\
\hline & Maternal education & 0.045 & $-0.150,0.585$ & 0.092 & $0.095,0.897$ & 0.100 & $0.120,0.729$ & 0.054 & -0.1100 .641 \\
\hline & Maternal MUAC & 0.113 & $0.189,0.985$ & 0.057 & $-0.106,0.794$ & 0.136 & $0.305,0.983$ & 0.091 & $0.077,0.895$ \\
\hline & Women's dietary diversity & -0.040 & $-0.516,0.166$ & 0.032 & $-0.216,0.534$ & -0.031 & $-0.402,0.161$ & -0.051 & $-0.578,0.122$ \\
\hline
\end{tabular}

\footnotetext{
Children's dietary diversity was removed from the model due to collinearity with women's dietary diversity
}

${ }^{a}$ Model summary $\left(R=0.240 ; \mathrm{R}^{2}=0.057\right.$; adjusted $\mathrm{R}$ square $=0.046$; Std. Error of the estimate $=1.973$; Durbin Watson $\left.=1.719\right)$

${ }^{\mathrm{b}}$ Model summary $\left(R=0.247 ; R^{2}=0.061\right.$; adjusted $R$ square $=0.050$; Std. Error of the estimate $=2.242 ;$ Durbin Watson $\left.=1.681\right)$

${ }^{c}$ Model summary $\left(R=0.234 ; R^{2}=0.055\right.$; adjusted $R$ square $=0.044 ;$ Std. Error of the estimate $=1.745 ;$ Durbin Watson $\left.=1.740\right)$

${ }^{\mathrm{d}}$ Model summary $\left(R=0.217 ; R^{2}=0.047\right.$; adjusted $R$ square $=0.035$; Std. Error of the estimate $=2.050$; Durbin Watson $\left.=1.675\right)$

Source: Self-calculation of micro-data from Survey of Ethiopia 2016 (GROW) 
colleagues [29] found similar trends, with older children demonstrating a higher risk of stunting than younger children. Conversely, this study found the youngest age group had the highest risk of low BMI-for-age. Limited studies explaining this trend are available, thus this study emphasizes the importance of findings explaining the complex nature of stunting and low BMI-for-age.

In terms of children diarrhea, neither children with diarrhea nor those without showed statistical association to the prevalence of stunting, wasting, underweight, and BMI-for-age. A study in rural Rwanda found similar results, the risks of stunting and wasting in children with diarrhea were not significantly different than their counterparts [30]. While diarrhea is a contributing factor to undernutrition, it alone does not fully explain stunting, wasting, undernutrition, and BMIfor-age, particularly when the reference period is relatively short (14 days) [31].

No significant differences in the risks of stunting, wasting, undernutrition, and BMI-for-age were seen amongst children with low and high dietary diversity scores. A 2013 study conducted by Ali and colleagues in Ethiopia, Vietnam, and Bangladesh [32] also found no representing association between child dietary diversity and anthropometric indicators; meaning that child dietary diversity is unlikely to have a large enough influence on nutrition to impact anthropometric indicators.

Children who defecated in the open had a significantly higher risk of having low BMI-for-age, but no significant differences when considering risks of wasting, stunting, or undernutrition. While this research only found significant associations between BMI-for-age and open defecation, it is complimented by previous researches in developing countries which found defecation in the open posing as threats for child linear growth [33]. The mechanisms behind this were attributed to diminished appetite, impaired nutrient absorption, and increased nutrient losses due to diarrhea [34]. Regional differences in the risks of stunting, wasting, undernutrition, and low BMI-for-age were presented in the previous section; children living in West Hararghe had the lowest risks of all four indicators when compared to those in Afar and East Hararghe. The poorest nutritional status of the children living in the Afar region may be reflective of the political disregard and poor living standards in the region [35].

Children with mothers who had no formal education had a higher risk of wasting, underweight, and low BMIfor-age, but not stunting. While some studies have found maternal education to be associated with all anthropometric indicators [36], others have found maternal education to be associated with only some anthropometric indicators. A study conducted in Ghana demonstrated the association between maternal knowledge and the child's long-term wellbeing (height-for-age), but not with underweight [37]. The relationship between maternal education and anthropometric indicators may affect a child differently long-term and during an acute illness, explaining the fluctuations seemed in the child's growth indicators.

Similar to education, maternal MUAC was significantly associated with child wasting, underweight, and low BMI-for-age, but not stunting. A recent study demonstrated that beyond maternal weight as a predictor of child nutrition status, the mother's vitamin and mineral status also play a role. The study found that mothers lacking certain nutrients in their breastmilk were likely to have children who were stunted. Conversely, mothers with no deficiencies of nutrients in their breastmilk did not have children that were significantly more stunted [38]. Since MUAC is an indicator of malnutrition that does not take into account specific nutrient deficiency, this may explain why maternal MUAC does not have the same effect on all the child anthropometric indicators. Maternal dietary diversity, much like the child's dietary diversity, was not found to be significantly associated with any of the child's anthropometric indicators.

In this study, analyses were carried out to explore the determinants of malnutrition that are profoundly related to child mortality in Ethiopia. The superior nutritional statues of girls under the same household conditions warrant further investigations. As confirmed in this study, stunting, wasting, undernutrition, and low BMIfor-age remains alarming in Ethiopia. Highlighting the factors influencing child undernutrition will help inform future policies and programs designed to approach this major problem in Ethiopia.

\section{Limitations}

Due to the cross-sectional nature of this study, the direction of associations cannot be firmly established. Additionally, constrained by the short reference period for diarrhea, the long-term association between diarrhea and child nutrition may not be representative. Lastly, it is suggested that future research is to focus on the influence of interactions between independent variables on the child anthropometric indicators.

\section{Conclusion}

This study found that maternal and children's characteristics influence the anthropometric indicators. Results showed that child's sex, age, region, open defecation, and maternal MUAC significantly increases the risk of wasting, stunting, undernutrition, and/or BMI-for-age. Importantly, maternal dietary diversity was not significant amongst other determinants of children's anthropometric statues. Given the numerous child anthropometric indicators available, this study highlights the influence of 
Table 4 Test of data normality

\begin{tabular}{lllllllll}
\hline & \multicolumn{3}{l}{ Kolmogorov-Smirnov } & & \multicolumn{5}{l}{ Shaprio-Wilk } \\
\cline { 2 - 3 } & Stataitics & df & sig & & Stataitics & df & sig \\
\hline Wasting & 0.020 & 917 & 0.200 & & 0.996 & 917 & 0.009 \\
Stunting & 0.033 & 917 & 0.021 & & 0.987 & 917 & 0.000 \\
Underweight & 0.026 & 917 & 0.143 & & 0.998 & 917 & 0.213 \\
BMl & 0.020 & 917 & 0.200 & & 0.996 & 917 & 0.023 \\
\hline
\end{tabular}

Source: Self-calculation of micro-data from Survey of Ethiopia 2016 (GROW)

controlling variables such as, sex, age, and region used for nutritional status in our study. Thus, caution must be used when interpreting research using single indicators to draw conclusions on child nutrition status.

\section{Endnotes}

${ }^{1}$ In the regression analyses, age was used in a scale level.

${ }^{2}$ This question was used: Do any of your household members defecate in the bush/field? With yes and no answers.

${ }^{3}$ Although this indicator is recommended for children under 24 months, children up to 59 were added in the analyses.

${ }^{4}$ Normality of data was analyzed using SPSS (V.24). Table of data normality presented in Table 4 .

\section{Acknowledgements}

Authors of this manuscript thank the colleagues from CARE Canada, Global Affairs Canada, Ningyuan Wang (summer intern) and McGill Institute for Global Food Security.

\section{Funding}

This manuscript is based on the funding provided by Global Affairs Canada through CARE Canada.

\section{Availability of data and materials}

The data is available in the Global Affairs Canada, CARE Canada and McGill Institute for Global Food Security just for members of project and it is not available for public access.

\section{Authors' contributions}

DA contributed substantially in data analyses and drafting the manuscript. $\mathrm{AS}$ and NE reviewed literature and wrote the introduction part. EA contributed substantially to the interpretation of the results and discussion. HM and PC contributed to the discussion partly and conclusion and they also gave final approval of the final version of the manuscript. All authors read and approved the final manuscript.

\section{Ethics approval and consent to participate}

Ethical clearance was obtained from the McGill University IRB review board and the Oromia Health Bureau in Ethiopia'. Government sector offices at Zonal and Woreda level were officially communicated prior to data collection. Up on arrival at field, enumerators informed Kebele leaders about the purpose, content and sampling methods of the study. Study participants were informed about the purpose of the baseline study and how the results will be used. They are clearly informed about their right to refuse to take part, terminate the interview at any point or not answering any question. Using a standard consent form provided by CARE, consent ( $99.8 \%$ verbal) was received from each study participant before each interview. For anthropometric measurement, consent was received from the mother/ caregiver before measuring weight and height/length of a child. Interviews and were conducted at household level in settings that ensure privacy.

\section{Competing interests}

The authors declare that they have no competing interests.

\section{Publisher's Note}

Springer Nature remains neutral with regard to jurisdictional claims in published maps and institutional affiliations.

\section{Author details}

${ }^{1}$ McGill Institute for Global Food Security, Macdonald Campus, 21111 Lakeshore Road, Ste-Anne-de-Bellevue, QC H9X 3V9, Canada. ${ }^{2}$ Master student in School of Dietetics and Human Nutrition in McGill University, Montreal, Canada.

Received: 26 April 2017 Accepted: 1 February 2018

Published online: 15 May 2018

References

1. Unicef (2015) improving child nutrition: the achievable imperative for global progress. 2013. ISBN: 978-92-806-4686-3.

2. Aguayo V, Badgaiyan N, Dzed L. Determinants of child wasting in Bhutan. Insights from nationally representative data. Public Health Nutr. 2017;20(2): $1-10$.

3. Black R, Victora C, Walker S, et al. Maternal and child undernutrition and overweight in low-income and middle-income countries. Lancet. 2013; 382(9890):427-51.

4. Paul CM, Mythili G, Paul W, et al. A cross-sectional study on the prevalence of acute and chronic malnutrition among children in the under-five children in a Chennai based population. Glob J For Res Anal. 2017:5(11):76-8

5. Akinbami L, Kit B, Carroll M, et al. Trends in anthropometric measures among US children 6 to 23 months, 1976-2014. Pediatrics. 2017;139(3): e20163374

6. WHO (2012) Nutrition landscape information system (NLIS) country profile indicators: interpretation guide.

7. Onis M, Branca F. Childhood stunting: a global perspective. Mater Child Nutr. 2016:12(S1):12-26.

8. Candler T, Costa S, Heys M, et al. Prevalence of thinness in adolescent girls in low-and middle-income countries and associations with wealth, food security, and inequality. J Adolesc Health. 2017;60(4):447-54.

9. FAO (2016) Ethiopia: situation report-February 2016. Retrieved from: http:// www.fao.org/fileadmin/user_upload/emergencies/docs/FAO\%20Ethiopia_ El\%20Nino\%20Situation\%20Report_February\%202016.pdf.

10. Unicef (2016) ETHIOPIA humanitarian situation report \#4. Retrieved from: https://www.unicef.org/ethiopia/UNICEF_Ethiopia_CO_Humanitarian_Sitrep_ April_2016.pdf.

11. Getahun Z, Urga K, Ganebo T, et al. Review of the status of malnutrition and trends in Ethiopia. Ethiop J Health Dev. 2017:15(2):1-25.

12. WFP (2013) The cost of hunger in Ethiopia: implications for the growth and transformation of Ethiopia. Reterieved from: http://reliefweb.int/sites/ reliefweb.int/files/resources/FINAL\%20Ethiopia\%20\%20COHA\%20Summary\%20Report\%20June\%2028.pdf.

13. Rice A, Sacco L, Hyder A, et al. Malnutrition as an underlying cause of childhood deaths associated with infectious diseases in developing countries. Bull World Health Organ. 2000;78(10):1207-21.

14. Teshome B, Kogi-Makau W, Getahun Z, et al. Magnitude and determinants of stunting in children underfive years of age in food surplus region of Ethiopia: the case of west gojam zone. Ethiop J Health Dev. 2009:23(2):98-106.

15. Arimond M, Ruel M. Dietary diversity is associated with child nutritional status: evidence from 11 demographic and health surveys. J Nutr. 2004; 134(10):2579-85.

16. USAID (2012) Maternal dietary diversity and the implications for children's diets in the context of food security. Retrieved from: http://iycn.wpengine. netdna-cdn.com/files/YYCN_Brief_Maternal_Dietary_Diversity0112.pdf.

17. Eshete $H$, Abebe $Y$, Loha $E$, et al. Nutritional status and effect of maternal employment among children aged 6-59 months in Wolayta Sodo town, southern Ethiopia: a cross-sectional study. Ethiop J Health Sci. 2017;27(2): $155-62$.

18. Alemu Z, Ahmed A, Yalew A, et al. Individual and community level factors with a significant role in determining child height-for-age $Z$ score in east 
Gojjam zone, Amhara regional state, Ethiopia: a multilevel analysis. Arch Pub Health. 2017;75(1):27.

19. Blössner M, De Onis M, Prüss-Üstün A, et al. Quantifying the health impact at national and local levels. Geneva: WHO; 2005. http://www.who.int/ quantifying_ehimpacts/publications/MalnutritionEBD12.pdf?ua=1

20. Fikadu T, Assegid S, Dube L. Factors associated with stunting among children of age 24 to 59 months in Meskan district, Gurage zone, South Ethiopia: a case-control study. BMC Public Health. 2014;14(1):800.

21. Umeta $\mathrm{M}$, West $\mathrm{CE}$, Verhoef $\mathrm{H}$, et al. Factors associated with stunting in infants aged 5-11 months in the Dodota-Sire District, rural Ethiopia. J Nutr. 2003;133(4):1064-9.

22. Fenn B, Bulti A, Nduna T, et al. An evaluation of an operations research project to reduce childhood stunting in a food-insecure area in Ethiopia. Public Health Nutr. 2012;15(9):1746-54.

23. Dearden K, Schott W, Crookston B, et al. Children with access to improved sanitation but not improved water are at lower risk of stunting compared to children without access: a cohort study in Ethiopia, India, Peru, and Vietnam. BMC Public Health. 2017;17:110.

24. Kennedy G, Ballard T, Dop MC (2011) Guidelines for measuring household and individual dietary diversity. Retrieved from: http://www.fao.org/3/ai1983e.pdf:: food and agriculture Organization of the United Nations.

25. Ballard T, Kepple A, Cafiero C. The food insecurity experience scale: development of a global standard for monitoring hunger worldwide. Rome: FAO; 2013.

26. WHO. Indicators for assessing infant and young child feeding practices: part 1: definitions: conclusions of a consensus meeting held 6-8 November 2007. Washington; 2008. Retrieved from: http://apps.who.int/iris/bitstream/ 10665/43895/1/9789241596664_eng.pdf

27. Unicef (2014) Global nutrition database, based on multiple Indicator cluster surveys (MICS), demographic and health surveys (DHS) and other nationally representative surveys. Retrieved from: http://data.unicef.org/topic/nutrition/ malnutrition/\#

28. Olack B, Burke $H$, Cosmas $L$, et al. Nutritional status of under-five children living in an informal urban settlement in Nairobi, Kenya. J Health Popul Nutr. 2011;29(4):357-63.

29. Gebreyesus S, Mariam D, Gebreyesus S, et al. Local spatial clustering of stunting and wasting among children under the age of 5 years: implications for intervention strategies. Public Health Nutr. 2016;19(8):141727.

30. Sinharoy S, Schmidt W, Boisson S, et al. Child diarrhoea and nutritional status in rural Rwanda: a cross-sectional study to explore contributing environmental and demographic factors. Trop Med Int Health. 2016;21(8): 956-64.

31. Dube $L$, Taha $M$, Wondaferash $M$, et al. Prevalence of undernutrition and associated factors among children aged between six to fifty nine months in Bule Hora district, South Ethiopia. BMC Public Health. 2015;15(1):41.

32. Ali $D$, Saha $K$, Nguyen $P$, et al. Household food insecurity is associated with higher child undernutrition in Bangladesh, Ethiopia, and Vietnam, but the effect is not mediated by child dietary diversity. J Nutr. 2013;143(12):2015-21.

33. Vyas S, Kov P, Smets $S$, et al. Disease externalities and net nutrition: evidence from changes in sanitation and child height in Cambodia, 20052010. Econ Hum Biol. 2016;23(2):235-45.

34. Rah JH, Cronin A, Badgaiyan B, et al. Household sanitation and personal hygiene practices are associated with child stunting in rural India: a crosssectional analysis of surveys. BMJ Open. 2015;5(2):e005180.

35. Bryden M. Situation Report on Region 2 (Afar National Regional State). 1996. Retrieved from: http://www.africa.upenn.edu/eue_web/AFAR1A.htm: Emergencies unit for Ethiopia.

36. Abuya B, Onsomu E, Kimani J, et al. Influence of maternal education on child immunization and stunting in Kenya. Matern Child Health J. 2011; 15(8):1389-99.

37. Saaka M. Relationship between mothers' nutritional knowledge in childcare practices and the growth of children living in impoverished rural communities. J Health Popul Nutr. 2014;32(2):237-48.

38. Black R, Allen L, Bhutta Z, et al. Maternal and child undernutrition: global and regional exposures and health consequences. Lancet. 2008;371(9608): $243-60$

\section{Submit your next manuscript to BioMed Central and we will help you at every step:}

- We accept pre-submission inquiries

- Our selector tool helps you to find the most relevant journal

- We provide round the clock customer support

- Convenient online submission

- Thorough peer review

- Inclusion in PubMed and all major indexing services

- Maximum visibility for your research

Submit your manuscript at www.biomedcentral.com/submit

) Biomed Central 